Revue d'histoire de l'Amérique française

REVUE D.HISTOIRE DE L'AMÉRIQUE FRANÇAISE

\title{
ANDRÈS, Bernard, Les mémoires de Pierre de Sales Laterrière suivi de correspondances (Montréal, Éditions Triptyque, 2003), $320 \mathrm{p}$.
}

\section{Sophie Imbeault}

Volume 58, numéro 2, automne 2004

URI : https://id.erudit.org/iderudit/011123ar

DOI : https://doi.org/10.7202/011123ar

Aller au sommaire du numéro

Éditeur(s)

Institut d'histoire de l'Amérique française

ISSN

0035-2357 (imprimé)

1492-1383 (numérique)

Découvrir la revue

Citer ce compte rendu

Imbeault, S. (2004). Compte rendu de [ANDRÈS, Bernard, Les mémoires de Pierre de Sales Laterrière suivi de correspondances (Montréal, Éditions Triptyque, 2003), 320 p.] Revue d'histoire de l'Amérique française, 58(2), 285-286. https://doi.org/10.7202/011123ar d'utilisation que vous pouvez consulter en ligne.

https://apropos.erudit.org/fr/usagers/politique-dutilisation/ 
ANDRÈS, Bernard, Les mémoires de Pierre de Sales Laterrière suivi de correspondances (Montréal, Éditions Triptyque, 2003), 320 p.

$\mathbf{U}_{n}$ jeune noble français qui vient s'installer au Canada quelques années après la Conquête, voilà qui a de quoi surprendre. Tel est pourtant le parcours que retracent ces Mémoires qui font l'objet d'une réédition commentée par Bernard Andrès qui nous font découvrir, au fil d'un récit autobiographique, le détail de la vie mouvementée de cette personne.

Pierre de Sales Laterrière (1743-1815) est quelqu'un d'éminemment intéressant à côtoyer par le biais de cette œuvre rédigée vers 1812-1815 et publiée en 1873. On comprend pourquoi Bernard Andrès s'attache tant au médecin, auquel il a déjà consacré une biographie et qu'il considère comme le premier mémorialiste canadien. Bien que l'on sente parfois une certaine exagération dans le propos, Laterrière nous fait souvent sourire au passage d'une anecdote par sa plume colorée, soulève notre intérêt lorsqu'il aborde des thèmes comme l'importance du réseau social et lorsqu'il traite de questions comme le divorce et l'homosexualité.

Bernard Andrès accompagne l'œuvre d'un appareil critique complet et d'une correspondance de prison inédite. Par surcroît, en voulant réhabiliter le personnage, il contribue également, comme d'autres cherchent à le faire actuellement, à jeter un regard nouveau sur la période de l'aprèsConquête.

On découvre, grâce à ce document, un personnage singulier confronté aux événements qui rythment son époque ainsi qu’à ses contemporains connus et moins connus. Ultimement, Laterrière exprime surtout des sentiments et des idées à l'égard de faits historiques. Voilà l'exemple éloquent d'une pièce que tout historien souhaiterait posséder lorsqu'il entreprend 
une étude biographique et qui captivera sans doute tous ceux qui s'intéressent à la période.

SOPHIE IMBEAULT

Québec

CHEAL, David, dir., Vieillissement et évolution démographique au Canada (Montréal, Les Presses de l'Université de Montréal, 2003), 298 p.

Vieillissement et évolution démographique au Canada (en anglais: Aging and Demographic Change in the Canadian Context), met l'accent sur la complexité et sur la diversité de la population des aînés et constitue un ajout fort utile aux études des dernières années de chercheurs qui ont entrepris de réagir aux visions pessimistes selon lesquelles le vieillissement de la population présageait la venue d'une crise de société; nuançant ainsi notre compréhension du vieillissement. Dirigé par David Cheal, professeur de sociologie à l'Université de Winnipeg, l'ouvrage est composé d'essais de chercheurs de divers champs: sociologie, gérontologie, psychologie, économie politique, loisirs, littérature et relations industrielles. Susan McDaniel définit le concept d'interconnexions intergénérationnelles et montre en quoi il peut servir de cadre pour "clarifier questions et orientations cruciales en matière de politique». Douglas Thorpe se penche sur le rôle du langage dans l'interprétation du vieillissement et de l'âgisme (discrimination envers les personnes âgées). Ingrid Arnet Connidis étudie le contexte plus vaste de la vie familiale et de la participation au monde du travail et leur relation à la question de l'équité intergénérationnelle. Joel Prager traite de l'impact du vieillissement de la population sur l'économie et sur le travail en présentant différentes théories concernant la démographie et la productivité. Marty Thomas et Rosemary Venne analysent les travaux américains et canadiens sur l'emploi du temps afin de découvrir dans quelle mesure les Canadiens équilibrent travail et loisirs, particulièrement dans la vieillesse. Finalement, Joseph Tindale, Joan Norris et Krista Abbott livrent un essai sur la négociation de la réciprocité en matière de relations familiales et intergénérationnelles durant toute une vie.

L'ouvrage propose des perspectives nouvelles et importantes sur le vieillissement et le changement démographique en utilisant enquêtes et données de recensements. Un des thèmes majeurs de ce recueil touche à la nécessité de saisir la continuité de la vie humaine, de comprendre les 